\title{
Against Nature: How Arguments about the Naturalness of Marriage Privilege Heterosexuality
}

\author{
Elizabeth R. Cole* and Lanice R. Avery \\ University of Michigan
}

\section{Catherine Dodson}

Michigan State University

\section{Kevin D. Goodman}

University of Michigan

This article examines the public debate over marriage law to investigate how arguments based on claims about what is natural privilege some relationships while stigmatizing others and justifying discriminatory policies toward sexual minorities. Articles about same-sex marriage appearing in major newspapers were content-coded according to absence or presence of four dimensions of naturalness: change over time, norms, procreation, and welfare of children. Arguments invoking change over time were most frequent (39\%), and procreation appeared least (10\%). The use of arguments based on the moral status of marriage was associated with the use of each of the four dimensions based on naturalness. Mentions of race, including comparisons to racial struggles, appeared in $20 \%$ of the articles, making them just as common as child welfare. Results are discussed in terms of the power of the concept of naturalness to legitimize and maintain privilege, and the intersectionality of race and sexual orientation.

Peggy McIntosh's foundational paper on privilege (1988) is most often discussed as an interrogation of how unearned advantages make whiteness invisible; however, McIntosh also observed that other groups enjoy analogous advantages and she offered a short list of heterosexual privileges similar to her well-known

\footnotetext{
*Correspondence concerning this article should be addressed to Elizabeth R. Cole, Women's Studies Department, 204 S. State Street, Ann Arbor, MI 48109-1290. [e-mail: ecole@umich.edu].

This research received grant funding from the Rackham Graduate School of the University of Michigan.
} 
inventory comprising the "invisible knapsack" of whiteness. Although McIntosh did not explicitly name legal marriage as one of the benefits, she did point out that heterosexual privilege makes men and women who form households together seem "normal" and that onlookers feel no need to question such arrangements (Pratto \& Stewart, 2012). In other words, a key tool in the knapsack of heterosexual privilege is the entrenched and nearly unassailable assumption that such relationships are natural.

However, in the United States the past decade has seen a flurry of legal and political activity aimed on one side to reconsider, and on the other, to fortify the contours of marriage law. As of October 2011, Massachusetts, Connecticut, Iowa, Vermont, New Hampshire, and New York are the only U.S. states that issue marriage licenses to same-sex couples (in addition to the District of Columbia), whereas 37 states have statutes defining marriage as between one man and one woman (National Conference of State Legislatures, 2011). Indeed, contests over the legal recognition of same-sex relationships are taking place around the world (Fingerhut, Riggle, \& Rostosky, 2011), even as the forms these controversies take are culturally specific (e.g., van Zyl, 2011). Clearly, we are at a moment when heterosexual privilege is highly visible and contested (Montgomery \& Stewart, 2012).

In public debates about marriage, the idea of naturalness has often been used to privilege opposite-sex, and earlier, same-race, relationships and to justify discrimination against sexual and racial minorities. Cohen's (1997) definition of heteronormativity highlights how perceptions of what is natural play a role in maintaining privilege: "[heteronormativity consists of] localized practices and centralized institutions that legitimize and privilege heterosexuality and heterosexual relationships as fundamental and 'natural' within society" (p. 440). Indeed, in many U.S. states, laws banning nonprocreative sexual behavior, including homosexual behavior, sometimes termed the offending acts as "crimes against nature" (Curtis \& Gilreath, 2008).

The rhetorical invocation of what is natural as a justification for exclusionary marriage policies appears largely unchanged in marriages debates in the U.S. separated by more than 40 years. Laws against interracial marriage were found to be unconstitutional in 1967 by the U.S. Supreme Court's ruling in Loving $v$. Virginia. From today's vantage point, the arguments against interracial marriage, which typically invoked the concept of naturalness grounded in either the rhetoric of science (Newman, 2004) or religion, starkly demonstrate the degree to which the idea of the natural is socially constructed and historically contingent. For example, a dissenting opinion in an early interracial marriage case used expert testimony to conclude "crossing of the primary races leads gradually to retrogression and eventual extinction of the resultant type unless it is fortified by reunion with the parent stock" (Newman, 2004 p. 539), a view that most today would view as motivated by racism rather than scientific objectivity. 
This study explores the ways naturalness arguments have been used recently to privilege heterosexual marriage, thus justifying discrimination against sexual minorities in the public debates about marriage. We reviewed scholarship on the history of the controversies regarding same-sex and interracial marriage to identify argumentative dimensions based on the concept of naturalness and then used empirical methods to assess the prevalence of each argument in recent newspaper accounts of the legal and political controversies concerning same-sex marriage. In addition, we coded the articles for arguments concerning the moral status of marriage and mentions of race to assess the relative use of these arguments, and to examine whether these other types of arguments systematically occurred in articles with naturalness rhetoric.

\section{Naturalistic Fallacy}

Marriage policy arguments that invoke naturalness often rely on a naturalistic fallacy. This fallacy takes the form "what is natural is morally good," and is fallacious because there is no logical basis for the claim that moral positions (what ought to be) follow from descriptions of nature (what is). Friedrich (2005) found that many students made naturalistic fallacy errors when quizzed about the implications of a research report, and this tendency increased when they were asked to recall the report three weeks after reading it. To the extent that this fallacy is widespread, arguments based on claims about the naturalness of certain unions will be effective.

Scholarship on the history of justifications for marriage law might be understood in terms of the naturalistic fallacy in practice. Pascoe (2009) detailed the history of how U.S. miscegenation law paralleled local perceptions of which races were viewed as naturally inferior. In the North and South laws prohibited marriages between Blacks and Whites, whereas in the West, the extensive list of "races" prohibited from marrying Whites included American Indian, Chinese, Japanese, and Hindu. In contrast, in the recent same-sex marriage debates much attention has been paid to social science research in attempts to establish what type of household fosters positive child development. Newman (2004) drew parallels between the use of pseudo-scientific research in support of miscegenation laws and the use of social science research purporting that two opposite sex parents are necessary for children's sex role development to oppose same-sex marriage in court cases. Both arguments commit the naturalistic fallacy as they contend that because racial difference/gender differentiation is natural, marriage law should permit only unions that maintain this difference/differentiation. Thus, the naturalistic fallacy represents a mechanism to explain why rhetorical arguments premised on the concept of naturalness can be expected to be common and persuasive. 


\section{The Symbolism of the Natural}

In her discussion of the use of "the natural" in relation to sexology, Tiefer (1995) adopted Williams' (1983) explanation of the concept of "nature" to explain its dynamic and powerful rhetorical application to issues of gender and sexuality. Williams noted that the term nature "is perhaps the most complex word in the language" (p. 291), and has multiple meanings rooted in both historical and contemporary use. The term is sometimes used to refer to an essential character of something, that is, a metaphor for bedrock or foundation. Bennett, Grossberg, and Morris (2005) noted that this sense of the term implies that what is natural is immutable and fixed. Nature also is used to describe an inherent force, suggesting an inviolable order or plan, as in the idea of "mother nature" or intelligent design. As well, the term is used to refer to the material and tangible world, and things considered natural in this way are thought to be distinct from culture or human creation. Taken together, these three meanings imbue the idea of the "natural" with tremendous rhetorical authority to legitimize anything so deemed (Tiefer, 1995).

The rhetorical use of "the natural" is evident in popular texts and the discourse of both laypeople and experts related to such topics as menstruation (Gunsen, 2010), breastfeeding (Locke, 2009), sex and marriage (McMillan, 2004), and love (Martin \& Kayzak, 2009). Lock and Kaufert (1998) argued that naturalness is strategically deployed in discourse about institutions, relationships, and identities to reinforce and challenge existing power structures. In each of these examples, assertions about what is natural are used to legitimize whatever behavior is privileged as correct, healthy, and untainted by "unnatural" influences.

In particular, in issues of marriage, love, and sex, "natural" arguments are used to constrain and differentiate. For example, McMillan's study of the Chinese marital sex self-help literature (2004) found "healthy" sex was strictly demarcated into what is natural and unnatural using pseudo-scientific arguments about natural behavior to imply what is "appropriate," "healthy," and "moral" sex: heterosexual, married, with traditional gender roles and cultural norms enforced. Heterosexual love is also exalted as natural in Disney animated films for children (Martin \& Kayzak, 2009). When characters of different sexes fall in love in these films they are visually depicted in settings suffused with imagery of the natural environment, including "fireflies, butterflies, sunsets, wind, and the beauty and power of nature..." (p. 325). In Disney films, the heterosexual love is so natural that all of surrounding nature comes alive and in synchronization with the music to celebrate the characters' love. These visual tropes emphasize the naturalness of the love on display.

However, the shifting rhetoric of the natural can be negotiated to either constrain or liberate; it has the authority to discriminate "normal" from "deviant" or to empower the oppressed. Sullivan-Blum (2006) found that in the debate over legitimacy of homosexuality and gay marriage between Christian conser- 
vatives and liberals, both used rhetoric about natural behavior to support their positions. Liberal Christians deployed naturalness arguments to support same-sex marriage, claiming homosexuality was inborn, thus natural. In contrast, conservative Christians simultaneously gave evidence for the naturalness of heterosexuality and opposite-sex couplings to deny legitimacy of homosexuality and same-sex marriage. Sullivan-Blum (2006) also addressed the experiences of homosexual churchgoers and discovered that they too utilized naturalness arguments, but some were troubled by the restrictive quality of this rhetoric because it misrepresented their experiences as sexual minorities. For example, bisexuality, fluidity of sexual orientation over time, and nonmonogamous sexual behaviors were repressed, ignored, and constrained in the discourse of the natural. She concludes that employing arguments of "'nature' simplifies the lived experiences of sexual desire in order to make of it useful arguments and representations. Such simplification, however, ignores or renders invisible portions of sexual experience to the detriment of LGBT Christians" (p. 213). Thus, although the rhetoric of the natural can be used to marshal support or opposition for sexual minorities and policies that benefit them, this research suggest such discourse comes at a price.

\section{Argumentative Dimensions of Naturalness in the Marriage Debates}

Based on review of the scholarship on the history of marriage law, four argumentative dimensions of naturalness were identified: change over time, norms, procreation, and welfare of children. Arguments that engage the dimension of "change over time" make claims about marriage arrangements as either fixed across time and place, or else as a social institution that can either evolve over time or differ across cultures. This argument is aligned with Williams' (1983) idea of nature as essential bedrock, immutable, and fixed. Yet Cott (2000) traced the history of U.S. marriage law revealing how the institution is deeply linked to cultural meanings of citizenship, and thus has been dramatically transformed, particularly in response to the changing status of African Americans and women. Thus, both arguments that support and those that challenge the legitimacy of same-sex marriage may engage the issue of whether marriage changes over time.

The idea that cultural "norms" that define deviance and depravity stem from a natural order is aligned with Williams' (1983) characterization of the natural as suggesting an inherent force or plan that orders the world. Often these claims are used to challenge changes to marriage laws through the use of the "slippery slope" argument. For example, Cahill (2004) demonstrated that the specter of allowing incest was used to discredit movements to legalize both interracial and same-sex marriage. In fact, in the 19th century, the same term, "intermarriage," was used to refer to both interracial and intrafamilial marriage. Psychological 
research on disgust suggests that appeals to the natural will be powerful arguments in the marriage debates. Disgust is naturalizing emotion that has been linked with prejudice (Hodson \& Costello, 2007) and the use of essentialism in racist discourse (Holtz \& Wagner, 2009). To their opponents, interracial sex and marriage threaten to undo the boundary between races, and same-sex marriage threatens the boundary between genders by challenging the idea of complementary gender norms (Greene, 2009). Cahill (2004) linked the parallels in legal and political discourse between incest, sex across race, and sex within gender to the psychological conceptualizations of disgust because the emotion is associated with boundary violations.

Two other forms that naturalness arguments take in the marriage debates have focused on procreation and the welfare of children. Crehan and Rickenbacker (2007) found that arguments based on procreation/child welfare were prevalent in coverage of same-sex marriage in both conservative and liberal publications between 1996 and 2006; however, they did not make a distinction between these two constructs. We argue this is a meaningful distinction because these arguments use the idea of the natural in different ways. Claims about the naturalness of procreation, which invoke the necessity of two people of different biological sexes to reproduce, are aligned with the idea of nature as manifest in material reality (Williams, 1983). Girgis, George, and Anderson (2010) made a typical argument of this type: although each individual is a complete biological entity, to be complete in the function of reproduction two opposite sex bodies must join through intercourse. The authors argue that therefore committed sexual relationships between pairs of biologically male and female persons should be privileged as "real marriage" (p. 252) over same-sex unions, though they explicitly included infertile heterosexual couples under this rubric because they take the idealized form. Arguments about procreation, grounded in assumptions of essential biological difference, harken back to those made in the debate over interracial marriage that Blacks were biological inferior to Whites and that intermarriage would compromise the resulting offspring (Johnson, 2009; Pascoe, 2009).

In contrast, arguments about the welfare of children are associated with the idea of nature as entailing an inviolable order or plan (Williams, 1983). These arguments typically either affirm healthy outcomes for children raised by same-sex couples (Kitzinger \& Wilkinson, 2004), or claim that children from such families suffer harm, including development of nonheterosexual sexual orientations in adulthood or emotional trauma from stigma associated with homophobia. Often social science evidence is marshaled to support these claims. Sullivan-Blum (2006) identified a similar line of argument in conversations with evangelical U.S. Christians, who claimed that gender differences in sexuality were natural, and heterosexual marriage is required to join men and women's complementary natures whereas taming men's inborn predisposition for promiscuity by tying them to family responsibilities. 


\section{Invoking Morality and Race}

Reading the literature on the marriage debates lead us to identify two other argumentative dimensions that do not rely on the concept of the natural: (1) those concerning the moral status of marriage, and (2) those mentioning racial aspects of this debate, including comparisons to struggles for racial equality. First, arguments about the moral status of marriage are of interest because, as Johnson (2009) observed, religious arguments have been used in court cases pertaining to both interracial marriage and same-sex marriage (see Blumenfeld \& Jaekel, 2012 for a discussion of Christian influence on secular U.S. institutions). In an early decision (1959) leading up to Loving v. Virginia, Judge Leon Bazile famously argued: "Almighty God created the races white, black, yellow, Malay and red, and he placed them on separate continents. ... the fact that he separated the races shows that he did not intend for the races to mix." More recently, the pronouncement that "God made Adam and Eve, not Adam and Steve," has been repeated countless times in opposition to same-sex marriage (a recent Google search turned up 23,200 websites including the phrase), and Crehan and Rickenbacker (2007) found that similar arguments increased in prevalence in Conservative publications between 1996 and 2006.

Second, same-sex marriage may be legitimated or challenged by comparison to race, either directly, by invoking the legal controversy over interracial marriage, or indirectly, by comparing the struggle for rights for sexual minorities to struggles for racial justice. The literature addressing the marriage debates within critical race and sexuality studies troubles the simple analogy between interracial and samesex marriage. For example, Novkov (2008) examined the legal history of these controversies to conclude that laws against interracial marriage were explicitly intended to preserve a view of citizenship based on white supremacy; in contrast, the laws preventing same-sex marriage mainly preserve gender norms and the necessity of heterosexuality. Nevertheless discussion of race in relation to samesex marriage is often invoked in the mass media (e.g., Greene, 2009; Johnson, 2009; Pascoe, 2009).

\section{This Study}

To understand how the concept of naturalness has been used in public debates about whether heterosexual relationships should be privileged by reserving the right to legal marriage, we conducted a quantitative content analysis of the argumentative dimensions present in coverage of same-sex marriage court cases in Massachusetts and California in American newspapers between 2004 and 2008. We coded four argumentative dimensions related to the naturalness of heterosexual unions: Change over time, norms, procreation and child welfare. The articles were also coded for arguments concerning race and the moral status of marriage. 
We investigated the following research questions: What is the relative prevalence of the arguments that rely on the concept of certain unions as natural, and how does their prevalence compare to arguments based on the moral status of marriage and mentioning race? Are there systematic patterns in the appearance of naturalness arguments in the same articles that use arguments based on moral status and comparison to race?

\section{Method}

We conducted a content analysis of articles from prominent national newspapers covering the status of same-sex marriage in the U.S. states of Massachusetts and California because they were the first to have legalized same-sex marriage. In Goodrich v. Department of Public Health (2004), the Massachusetts Supreme Court found that bans against same-sex marriage violated the equal protection clauses of its state constitution (Samar, 2005). The California Supreme Court challenged the constitutionality of state laws barring same-sex marriages In re Marriage Cases (2008) (later that year California voters approved Proposition 8, limiting marriage to opposite-sex couples; this law is still being challenged in the courts).

\section{Selection of Newspapers and Articles}

We compiled a systematic inventory of articles in major newspapers relating to same-sex marriage cases in Massachusetts and California, during a time period of intense public debate about marriage law. Using the top 100 daily newspapers in the United States according to circulation from the Editor and Publisher International Year Book (2008), 12 national newspapers with high-circulation rates were identified based on both circulatory prominence and regional proximity to the specified same-sex marriage court cases. We coded articles from: USA Today, Wall Street Journal, New York Times, New York Post, Washington Post, Houston Chronicle, San Francisco Chronicle, Star Tribune, Star-Ledger, Boston Herald, and Los Angeles Sentinel. Employing searches using the search terms "gay marriage" or "same-sex marriage" and "California" or "Massachusetts" in the Lexis-Nexis and Proquest Databases, 500 articles were identified from the periods between 20012004 and 2004-2008, corresponding to the height of controversy leading to the legalization of same-sex marriage in Massachusetts and California, respectively.

\section{Coding}

Two of the authors content-coded a random selection of approximately half the articles in the database $(N=273)$ for six argumentative dimensions (described below) according to presence (1) or absence (0). An advantage of using this binary 
coding strategy is that the inter-coder reliabilities are relatively high. A disadvantage of binary data is that the coding involves more measurement error, and there is a risk that correlations between such variables are lower than correlations between ordinal or interval variables (Semetko \& Valkenburg, 2000). The researchers double coded a subsample of $37 \%$ of the articles $(n=100)$ in five separate iterations throughout the coding process. Percent category agreement was computed by using the following formula from Winter (1973): $(2 \times$ the number of agreements on the presence of a category) / (number of a particular coding category scored by the coder A + number of a particular coding category scored by coder B). Percent category agreement across the six categories was $86 \%$.

\section{Coding Criteria}

Change over time was coded when statements argued or refuted that a given marriage arrangement has existed for an immeasurable time, or reflects longstanding (and thus, consensually agreed upon) practice. For example: "A marriage is a man and woman, which we've had 5,000-odd years to affirm," or "The definition of marriage is equally amenable to changing with the times. The concept is about love and commitment, not gender." We also coded claims and refutations that traditional marriage arrangements are universal and practiced "around the world."

Norms. Claims and refutations that same-sex marriage is abnormal, deviant, or disgusting were coded under this dimension, as were comparisons of homosexuality or same-sex marriage to other forms of relationships that are presented as implicitly immoral or unacceptable (e.g., incest, polygamy, or bestiality). For example: "If gay marriage, why not group marriage or the legal union of blood relations?" or "Why not pass a constitutional ban on polygamy? Or adultery? Both erode the "sanctity of marriage."

Procreation was coded when statements used or challenged biological reproduction as a rationale for marriage, or when marriage was described as founded on the biological complementarily of male and female bodies. Arguments that heterosexual marriage is not limited to people who are willing or able to reproduce (e.g., infertile, aged, or voluntarily childless) were also coded. Examples include: "[if same-sex marriage were legal] ... marriage would be understood as domestic partnership of two people linked by genital sex than as something associated with a biological bond between parents and children," or "[speaker] said the right to marry "has never been limited to those who plan or desire to have children."

Welfare of children was coded when articles described particular marriage arrangements as being healthy or preferred for raising children, or about the implications of exposing children to homosexuality. For example: "Once you stray too far from the idea that marriage is child-centered, you're going to get into 
an endless series of contradictions," or “... professional groups say two parents, whether heterosexual or homosexual, are preferable to single parent families."

Moral status was coded whenever articles made moral judgments, including citation of religious doctrine, as justification the appropriateness of marriage arrangements. Most mentions of the word "sanctity" were coded under this dimension. For example: "If judges insist on forcing their arbitrary will upon the people... Our nation must defend the sanctity of marriage."

Discussion of race. Arguments that compared same-sex marriage to struggles for racial equality, including interracial marriage (anti-miscegenation) laws/debates, civil rights, segregation or the abolition of slavery were coded here, as were any mention of racial aspects of this debate. For example: “ . . same-sex ruling relied heavily on the court's 1948 decision on interracial marriage ... the court was far ahead of public opinion." In addition, when comparisons were made, coders noted whether the comparison was to interracial marriage or to other struggles for racial equality.

\section{Results}

To assess the overall prevalence of arguments based on the concept of naturalness, a variable was constructed for each article that was coded 1 when any of the four dimensions related to natural were mentioned, and 0 if none of the categories were mentioned. A majority of the articles (52\%) included at least one such dimension. Proportions of the articles in which each of the argumentative dimensions appeared are presented in Table 1. Of the dimensions relying on the concept of natural, change over time was mentioned in more than one-third of the articles, making it the most frequently occurring argument in the dataset. Norms and welfare of children were the next most common dimensions, each occurring in about one-fifth of the articles. Arguments based on procreation occurred in only one-tenth of the articles.

Interestingly, claims based on the stability of current marriage arrangements (change) were invoked even more often than arguments based on religion (moral status), which appeared in just under one third of the articles. Also of note was that discussion of race appeared in one-fifth of the arguments, making it comparable in prevalence to both norms and welfare of children. Examination of the content of the arguments based on race revealed that of 36 articles in which comparisons to race were made, there were nearly as many mentions of struggles to end segregation and slavery (22) as there were comparisons to interracial marriage (24).

To investigate whether the argumentative dimensions tend to co-occur in the same articles, we calculated the phi-coefficient of association (used in the case of two dichotomous variables) between each dimension and every other (Table 1). Two patterns emerged. First, use of moral status arguments was significantly 
Table 1. Prevalence of, and Associations between (Phi-coefficients), Argumentative Dimensions in Same-Sex Marriage Articles

\begin{tabular}{lrrrrrrrr}
\hline Variable & Prevalence (\%) & 1 & 2 & 3 & 4 & 5 & 6 \\
\hline Argumentative dimensions based & & & & & & & \\
$\quad$ on naturalness & & & & & & \\
$\quad$ Change over time & $107(39 \%)^{\mathrm{a}}$ & - & & & & \\
$\quad$ Norms & $62(23 \%)$ & $.33^{* *}$ & - & & & \\
$\quad$ Procreation & $28(10 \%)$ & $.20^{* *}$ & .08 & - & & \\
$\quad$ Welfare of children & $55(20 \%)$ & $.30^{* *}$ & $.19^{* *}$ & $.34^{* *}$ & - & \\
Alternative argumentative & & & & & & & \\
$\quad$ dimensions & & & & & & & \\
$\quad$ Moral status & $55(31 \%)$ & $.28^{* *}$ & $.18^{* *}$ & $.27^{* *}$ & $.18^{* *}$ & - & \\
$\quad$ Discussion of race & $55(20 \%)$ & .10 & .10 & $.23^{* *}$ & $.16^{* *}$ & .12 & - \\
\hline
\end{tabular}

Note. Articles were selected using location specific search operators (California or Massachusetts), and articles were coded as relating to California $(\mathrm{N}=83)$, Massachusetts $(\mathrm{N}=131)$, or other $(\mathrm{N}=$ 59). Total prevalence includes occurrence across all articles.

${ }^{a}$ Chi-Square analysis indicated that the change over time argument was used significantly more frequently in articles about Massachusetts $(46 \%)$ than about California $(28 \%), \chi^{2}(1,214)=6.07^{*}$.

${ }^{*} p<.05 * * p<.01$. There were no differences by state on the other dimensions.

associated with all four dimensions based on conceptions of what is natural (change over time, norms, procreation, and welfare of children). Second, discussion of race was significantly associated with procreation and welfare of children.

\section{Discussion}

Content-coding of articles concerning same-sex marriage appearing in highcirculation newspapers revealed that slightly more than half the articles coded included at least one argument about the naturalness of certain relationships. Despite the acknowledgment among historians of the changing nature of marriage over time (Cott, 2000), the most common type of naturalness argument observed in these articles concerned the stability of current arrangements (one man, one woman). Of the text coded under the category change over time, $90 \%$ of the responses concerned the temporal stability of marriage laws, while only $10 \%$ mentioned consistency of marriage traditions across cultures and religions. Reviewing the text coded under change, we noted some thematic patterns. Many of the statements attempted to quantify the span of time during which marriage had remained unchanged (e.g., centuries-old, thousands of years, millennia). This rhetoric suggests that the continuity of history has immense magnitude, even weight. Most of the statements coded in this category argued by assertion rather than providing evidence, and this was especially true for claims that marriage arrangements were 
invariant across cultures. Finally, these statements often characterized same-sex marriage as inauthentic (using terms such as sham, counterfeit, and fake). These claims implicitly — and sometimes, explicitly—invoke a binary with what is real and natural (same-sex marriages "threaten to devalue the real thing"). One notable statement claimed, "Disregarding of anthropological evidence and redrawing the line of marriage to no longer be a man and a woman but simply just two consenting adults result[s] in a line in the blowing sand." Not only does this vivid imagery highlight the sense of the natural entailing a planful force that organizes the world (in contrast to an arbitrary line shifting in the sand), but also contrasts change in marriage law to the ideal of nature as a foundation or bedrock, a metaphor we saw repeatedly in text coded in this category. Those supporting same-sex marriage invoked this argumentative dimension much less often, and when they did, typically it was to deny the legitimacy of tradition as a justification for setting policy in the present, or to refute claims that change equated to social erosion.

The argument that marriage laws should continue unchanged from how they are believed to always have been is based on the assumption that the status quo should be privileged and that tradition is a social good. This line of rhetoric may be popular, particularly among opponents of same-sex marriage, precisely because it does not rely on religious justification, which may be challenged on the grounds of either the particularity of any religious tradition or the separation of church and state. The prevalence of the change over time argument is also noteworthy because stability is a key concept in defining something as natural rather than socially constructed and culturally dependent. This argumentation is related to the "existence bias" (Eidelman, Crandall, \& Pattershall, 2009) and the "status quo bias" (Anderson, 2003). This research suggests a mechanism to explain why naturalness should hold rhetorical power in relation to gender, the body and sexuality as well as the institution of marriage.

Review of the text coded under the second most prevalent dimension, norms, revealed this line of argument often took the form of the slippery slope, asserting that legalization of same-sex marriage "could lead to a legalization of incest, polygamy, or worse." Although explicit statements of disgust were rare, those using this argument to challenge same-sex marriage used words such as "sick," "impure," "deviate," and "sodomy," and others compared the legal recognition of same-sex unions to allowing crime such as prostitution and drug use, all suggesting opprobrium. Interestingly, those supporting same-sex marriage also invoked this dimension fairly often. Some of these statements were simple rejections of the idea that same-sex unions were deviant; however, many other instances were found in which anti-same-sex marriage policies were characterized as creating "second-class citizens," presumably beyond the "charmed circle" (Rubin, 1984) surrounding privileged and acceptable sexuality.

Arguments based on the welfare of children were also common, appearing in $20 \%$ of the articles. Review of text coded under this dimension suggested the 
typical arguments against same-sex marriage took two forms. One focused on the necessity of parents of each sex for optimum child development; the second raised concerns about exposing children to homosexuality, either through teaching them that same-sex unions are acceptable, or allowing them to be raised by homosexuals, whom these speakers implied were unfit to parent. This review also revealed that child welfare was the only argumentative dimension in which supporters of same-sex marriage commonly invoked the idea of the natural not to refute it, but to support a separate line of argument. Many of these statements were claims that recognition of same-sex marriage provided stability and legal protection for children.

In contrast, arguments based on innate biological differences between the sexes necessary for procreation appeared only half as often as child welfare. Most often these arguments were used by those opposed to same-sex marriage, often claiming that the purpose of sexuality is to unite male and female sexuality in procreation, thus invoking the sense of the natural as rooted in material reality. However, opponents also claimed this arrangement reflected a divine plan for creation. Thus this argumentative dimension engages two connotations of the natural identified by Williams (1983). When used by proponents of same-sex marriage, these arguments sometimes provided counterexamples to the claim that heterosexual marriage exists primarily for procreation, as in the case of couples marrying late in life or those who choose not to reproduce. It is also worth noting that associations between the argumentative dimensions indicated that text coded as procreation appeared in articles that also made arguments based on the moral status of marriage to a greater extent than the association between moral status and child welfare. These results suggest some nuanced differences in the use of argumentation based on procreation and welfare of children in the same-sex marriage debates, and thus complicate the findings of Crehan and Rickbacker (2007) who combined these concepts into one coding category and found they were particularly common in articles about same-sex marriage appearing in conservative outlets.

The fact that arguments about the moral status of marriage appeared in less than a third of the articles demonstrates that public debates over the legal status of same-sex marriage are not primarily about moral justifications, including the invocation of religion. However, it is notable that every argumentative dimension based on conceptions of what is natural was associated with the likelihood of providing arguments based on moral status. This suggests that the use of naturalness rhetoric is likely to be associated with religious justification. It is also the case that review of the text coded for each of the argumentative dimensions revealed that naturalness rhetoric was used more often to oppose same-sex marriage than to support it; welfare of children was the only coding category that approached parity.

Somerville (2005) cautions that facile comparisons of the debates over samesex marriage to the history of miscegenation law in the United States can lead us to 
overlook the ways race and sexuality have been mutually linked in the law. Thus it is notable that in this sample of articles concerning same-sex marriage, mentions of race were just as prevalent as those concerning the welfare of children, and more prevalent than those based on procreation. Review of the excerpts coded for race revealed that many invoked a symbolic comparison between the movements for legal same-sex marriage and racial struggles - not only to the struggle for interracial marriage but also to end segregation and even slavery-to legitimize the political cause of same-sex couples. Very rarely did text coded for mentions of race include any discussion of people who experience inequality based on both race and sexuality. Arguments that liken same-sex marriage to movements to end racial discrimination often do so to affirm the justness of their cause. However, because the race is invoked in a symbolic way rather than in discussion of families or couples, this usage obscures the fact that some members of sexual minority groups are also people of color who face discrimination and stigma that cannot be ameliorated by the legalization of same-sex marriage (Farrow, 2007). Consequently these race-based arguments run the risk of reinforcing racial privilege at the same time they ostensibly challenge privilege based on heterosexuality.

The results of this study must be understood in the context of the project's limitations. First, no systematic attempt was made to code the news stories as either supporting or challenging same-sex marriage, as most of the articles attempted to present a balanced perspective on the issue and thus included multiple and conflicting perspectives (Li \& Liu, 2010). Thus, these results cannot be understood as characterizing either the supporters or the challengers of same-sex marriage. Rather, our study provides a snapshot of the public debate as it was represented in mainstream newspapers at one historical moment. Public opinion on the issue of marriage rights has shown some change over time [particularly among the young, and particularly in California (Lewis \& Gossett, 2008)]. Similarly, the contours of this debate may be expected to take different forms in other states, regions of the United States, and nations, and thus the findings may not be generalizable to other contexts.

Presenting social arrangements as natural, such as marriages, family formations, or gendered divisions of labor, diverts attention from injustice and inequality and suggests that change is neither possible nor desirable. Moreover, naturalness rhetoric almost invariably reinforces certain statuses as privileged, even when invoked in an effort to challenge sexuality-based privilege. Notably, welfare of children arguments in support of same-sex marriage often asserted that children would benefit most from a two-parent family structure, regardless of the parents' gender. This rhetoric implicitly privileges two-parent families over single parent families. Naturalness discourses work together to privilege particular sexual pairings and familial arrangements, and they may make privilege less visible because inequality comes to be seen as not only inevitable, but appropriate. Our findings indicate that naturalness arguments are common to the public debates on same-sex 
marriage, appearing in half the articles sampled from major newspapers; in fact, they are more common than arguments about the moral status of such unions. Indeed, review of the coded texts presented here suggests that naturalness arguments are so prevalent, so difficult to refute because they are typically based on assertion rather than evidence, and also so multifaceted, that they may obviate the need for arguments about morality, religion and scripture in public debate about same-sex marriage.

Greene (2009) argued "marriages across forbidden social lines are intrinsically disruptive because they challenge not only the validity of the categories themselves, but the hierarchies of privilege and disadvantage the categories are presumed to legitimize" (p. 701). The rhetoric of the natural forcefully pushes back against these incursions by using apparently simple arguments that tap deep-seated psychological mechanisms of essentialism. Because the institution of marriage "works as a public ordering device," structuring "citizenship and exclusion," (Novkov, 2008, p. 361), understanding the rhetorical mechanisms used to legitimate exclusionary marriage policies is centrally important to challenging the exclusionary features of these policies.

\section{References}

Anderson, C. J. (2003). The psychology of doing nothing: Forms of decision avoidance result from reason and emotion. Psychological Bulletin, 129, 139-166. doi: 10.1037/0033-2909.129.1.139

Bennett, T., Grossberg, L., \& Morris, M. (2005). New keywords: A revised vocabulary of culture and society. Malden, MA: Blackwell.

Blumenfeld, W. J. \& Jaekel, K. (2012). Exploring levels of Christian privilege awareness among pre-Service teachers. Journal of Social Issues, 68, 128-144.

Cahill, C. M. (2004). Same-sex marriage, slippery slope rhetoric and the politics of disgust: A critical perspective on contemporary family discourse and the incest taboo. Northwestern University Law Review, 99, 1543-1611.

Cohen, C. J. (1997). Punks, bulldaggers and welfare queens: The radical potential of queer politics? GLQ: A Journal of Lesbian and Gay Studies, 3, 437-465. doi: 10.1215/10642684-3-4-437

Cott, N. F. (2000). Public vows: A history of marriage and the nation. Cambridge, MA: Harvard University Press.

Crehan, M. G., \& Rickenbacker, K. (2006-07). The changing debate on same-sex marriage in the United States. Michigan Feminist Studies, 20, 1-17.

Curtis, M. K., \& Gilreath, S. (2008). Tranforming teenagers into oral sex felons: The persistence of the crime against nature after Lawrence v. Texas. Wake Forest Law Review, 43, 155-221.

Editor \& Publisher international Yearbook. (2008). New York: Editor \& Publisher Co.

Eidelman, S., Crandall, C., \& Pattershall, J. (2009). The existence bias. Journal of Personality and Social Psychology, 97, 765-775. doi: 10.1037/a0017058

Farrow, K. (2007). Is gay marriage anti-Black? Retrieved from http://www.nathanielturner.com/ isgaymarriageantiblack.htm on December 16, 2010.

Fingerhut, A. W., Riggle, E. D. B., \& Rostosky, S. S. (2011). Same-sex marriage: The social and psychological implications of policy and debates. Journal of Social Issues, 67, 225-241. doi: 10.1111/j.1540-4560.2011.01695.x

Friedrich, J. (2005). Naturalistic fallacy errors in lay interpretations of psychological science: Data and reflections on the Rind, Tromovitch and Baserman (1998) controversy. Basic and Applied Social Psychology, 27, 59-70. doi: 10.1207/s15324834basp2701_6 
Girgis, S., George, R., \& Anderson, R. T. (2010). What is marriage? Harvard Journal of Law and Public Policy, 34, 245-287.

Greene, B. (2009). The use and abuse of religious beliefs in dividing and conquering between socially marginalized groups: The same-sex marriage debate. American Psychologist, 64, 698-709. doi:10.1037/0003-066X.64.8.698

Gunson, J. S. (2010). "More natural but less normal": Reconsidering medicalisation and agency through women's accounts of menstrual suppression. Social Science \& Medicine, 71(7), 1324-1331. doi:10.1016/j.socscimed.2010.06.041

Hodson, G., \& Costello, K. (2007). Interpersonal disgust, ideological orientations, and dehumanization as predictors of intergroup attitudes. Psychological Science, 18, 691-698. doi:10.1111/j.14679280.2007.01962.x

Holtz, P., \& Wagner, W. (2009). Essentialism and attribution of monstrosity in racist discourse: Rightwing Internet postings about Africans and Jews. Journal of Community \& Applied Social Psychology, 19, 411-425. doi:10.1002/casp.1005

In re Marriage Cases, 43 Cal. 4th 757, 183 P. 3d 384, 76 Cal. Rptr. 3d 683, 2008 Cal. LEXIS 5247 (2008).

Johnson, G. (2009). We've heard this before: The legacy of interracial marriage bans and the implications for today's marriage equality debates. Vermont Law Review, 34, 277-289.

Kitzinger, C., \& Wilkinson, S. (2004) Social advocacy for equal marriage: The politics of 'rights' and the psychology of 'mental health'. Analyses of Social Issues and Public Policy, 4, 173-194. doi:10.1111/j.1530-2415.2004.00040.x

Lewis, G. B. \& Gossett, C. W. (2008). Changing public opinion on same-sex marriage: The case of California, Politics \& Policy, 30, 4-30. doi:10.1111/j.1747-1346.2007.00092.x

Li, X., \& Liu, X. (2010). Framing and coverage of same-sex marriage in U.S. newspapers. Harvard Journal of Communications, 21, 72-91. doi:10.1080/10646170903501161

Locke, A. (2009). 'Natural versus taught': Competing discourses in antenatal breastfeeding workshops. Journal of Health Psychology, 14(3), 435-446. doi:10.1177/1359105309102200

Lock, M., \& Kaufert, P. A. (Eds.) (1998). Pragmatic women and body politics. Cambridge: Cambridge University Press.

Martin, K. A., \& Kazyak, E. (2009). Hetero-romantic love and heterosexiness in children's G-rated films. Gender \& Society, 23, 315-336. doi:10.1177/0891243209335635

McMillan, J. (2004). Doing it by the book: Natural tales of marriage and sex in contemporary Chinese marriage manuals. Sex Education, 4(3), 203-215. doi:10.1080/1468181042000243312

McIntosh, P. (1988). White privilege and male privilege: A personal account of coming to see correspondences through work in women's studies (Working Paper No. 189). Wellesley, MA: Wellesley Centers for Women.

Montgomery, S., \& Stewart, A. J. (2012). Privileged allies: Resistance to heteronormativity and lesbian and gay rights activism. Journal of Social Issues, 68, 162-177.

National Conference of State Legislatures (2011). Same-Sex Marriage, Civil Unions and Domestic Partnerships. Retrieved from http://www.ncsl.org/IssuesResearch/HumanServices/ SameSexMarriage/tabid/16430/Default.aspx on October 29, 2011.

Newman, S. A. (2004). Use and abuse of social science in the same-sex marriage debate. The New York Law School Law Review, 49, 537-560.

Novkov, J. (2008). The miscegenation/same-sex marriage analogy: What can we learn from legal history? Law \& Social Inquiry, 33, 345-386.

Pascoe, P. (2009). What comes naturally: Miscegenation law and the making of race in America. New York: Oxford University Press.

Pratto, F. \& Stewart, A. L. (2012). Group dominance and the half-blindness of privilege. Journal of Social Issues, 68, $28-45$.

Rubin, G. (1984). Thinking sex: Notes for a radical theory of the politics of sexuality. In C. S. Vance, (Ed.), Pleasure \& danger: Exploring female sexuality (pp. 267-319). Boston, MA: Routledge \& Kegan Paul.

Samar, V. J. (2005). Privacy and the debate over same-sex marriage versus unions. DePaul Law Review, $54,783-804$. 
Semetko, H., \& Valkenburg, P. (2000). Framing European politics: A content analysis of press and television news. Journal of Communication, 50, 93-109. doi:10.1111/j.1460-2466. 2000.tb02843.x

Somerville, S. (2005). Queer Loving. GLQ: A Journal of Lesbian and Gay Studies, 11, 355-370. doi: $10.1215 / 10642684-11-3-335$

Sullivan-Blum, C. R. (2006). "The natural order of creation": Naturalizing discourses in the Christian same-sex marriage debate. Anthropologica, 48, 203-215. doi:10.2307/25605311

Tiefer, L. (1995). Sexual biology and the symbolism of the natural. In Tiefer, L. (Ed.), Sex is not a natural act and other essays (pp. 31-40). Boulder, Co.: Westview Press, Inc.

van Zyl, M. (2011). Are same-sex marriages unAfrican? Same-sex relationships and belonging in post-apartheid South Africa. Journal of Social Issues, 67, 335-357. doi:10.1111/j.15404560.2011.01701.x

Williams, R. (1983). Keywords: A vocabulary of culture and society, Revised Edition. New York, NY: Oxford University Press.

Winter, D. G. (1973). The power motive. New York, NY: Free Press.

ELIZABETH COLE is Professor of Women's Studies and Psychology at the University of Michigan. Her research interests include intersectionality; class, race, and gender as social identities; the relationship between political attitudes and behaviors, particularly among African Americans and all women; and qualitative methods.

LANICE AVERY is a doctoral student in Psychology and Women's Studies at the University of Michigan. Her research explores contemporary constructions of sexuality among African American women. Specifically, her work examines the effects of negative stereotype endorsement and embodiment on sexual attitudes, beliefs, and behaviors among stigmatized groups.

CATHERINE DODSON recently finished her undergraduate degree in Psychology at Smith College. Her research interests concern the intersection of gender and multiracial identity formation, particularly with concern to social identity theory. She is currently a doctoral student at Michigan State University in the Personality and Social Psychology department, where her research focuses on intersectional analysis.

KEVIN GOODMAN is a doctoral student in Psychology and Women's Studies at the University of Michigan. His research focuses on methodological issues, theory, and experiences surrounding the intersections of (multi)racial and sexual minority identity. He is currently exploring essentialism and intersectional consciousness as barriers and strategies to promote healthy intergroup perceptions. 